www.ugb.org.br

\title{
AVALIAÇÃO MULTITEMPORAL DA SUSCEPTIBILIDADE EROSIVA NA BACIA DO RIO URUCUIA (MG) POR MEIO DA EQUAÇÃO UNIVERSAL DE PERDA DE SOLOS
}

\author{
Clarisse Lacerda Mata \\ Universidade de Brasília, Departamento de Geografia, Asa Norte, CEP 70910-900, Brasília, DF \\ clarisselacerda@gmail.com
}

Osmar Abílio de Carvalho Júnior

Universidade de Brasília, Departamento de Geografia, Asa Norte, CEP 70910-900, Brasília, DF osmarjr@unb.br

Ana Paula Ferreira de Carvalho

Instituto de Colonização e Reforma Agrária- INCRA SBN Quadra 1, Bloco D, Edifício Palácio do Desenvlovimento, sala 1620, CEP 70057-900, Brasília, DF ana.carvalho@incra.gov.br

Roberto Arnaldo Trancoso Gomes Universidade de Brasília, Departamento de Geografia, Asa Norte, CEP 70910-900, Brasília, DF robertogomes@unb.br

Éder de Souza Martins

Embrapa Cerrados - BR 020, km 18, CP 08223, CEP 73310-970, Planaltina, DF eder@cpac.embrapa.br

Renato Fontes Guimarães

Universidade de Brasília, Departamento de Geografia, Asa Norte, CEP 70910-900, Brasília, DF renatofg@unb.br

\section{Resumo}

A Equação Universal de Perda de Solos (EUPS) é um modelo de predição de perda de solo segundo um produto da erosividade da chuva, Fator R, da erodibilidade do solo, Fator K, do comprimento de rampa, Fator L, da declividade da vertente, Fator S, da cobertura e do manejo, Fator C, e das práticas conservacionistas, Fator P. Esta metodologia de predição de perda de solos, tem também tem sido utilizada como um instrumento de avaliação de risco à erosão e como medida de planejamento em bacias de uso agrícola. Assim, o presente trabalho tem por objetivo identificar as mudanças da erosão do solo na Bacia do Rio Urucuia, Minas Gerais, Brasil, através dos resultados da EUPS para 1987 e 2007. A Bacia do Rio Urucuia é tributária da Bacia do Rio São Francisco, com aproximadamente $25.000 \mathrm{~km}^{2}$, contribui com $10 \%$ de vazão e $18 \%$ da carga de sedimentos. A metodologia usou o SIG para obtenção do Fator Topográfico (LS) e o Sensoriamento Remoto para a determinação dos fatores de cobertura e 
manejo (C) e práticas conservacionistas (P). A classificação das imagens Landsat-TM foi feita pelo método ISODATA para dois anos, 1987 e 2007. A análise multitemporal determinou para a área estudada a ocorrência de mudanças significativas na erosão do solo, no final de vinte anos. O fator mais significativo para a degradação e erosão foi o aumento das áreas agrícolas. Os resultados mostram a distribuição espacial das distintas áreas propensas à erosão na bacia, onde práticas conservacionistas são fundamentais na prevenção da perda de solo por erosão. A análise é importante para o planejamento ambiental, e pode dar subsídio ao estabelecimento de cenários que visem o desenvolvimento sustentável da bacia.

Palavras-chave: processos superficiais; uso da terra, sistema de informação geográfica, sensoriamento remoto

\begin{abstract}
The Universal Soil Loss Equation (USLE) is an erosion model to estimate average soil loss being a product of rainfall runoff erosivity factor R, soil erodibility factor K, slope length factor L, slope steepness factor S, cover management factor C, and support practice factor P. Beyond this methodology predict loss soil, it has been extended as a useful tool for evaluating erosion risk and planning conservation measures in agricultural watersheds. Thus, the present work has aim to identify soil erosion changes in Urucuia river basin, Minas Gerais state, Brazil from USLE results in 1987 and 2007. The Urucuia's River Basin is a tributary of the São Francisco river Basin with approximately $25,000 \mathrm{~km}^{2}$, which contributes with $10 \%$ of the discharge and $18 \%$ of the sediment loads. The methodology used GIS tools in order to facilitate derivation of the topographic factor (LS) from DEM and remote sensing data to develop the land cover classifications and consequently both factors cover-management (C) and support practice (P). The TM Landsat images classification were made by ISODATA classifier for the two years, 1987 and 2007. The multitemporal analysis determined that there were significant changes about soil erosion in the study area in the latest twenty years. The most significant factor to degradation and erosion was the increase of agricultural areas. The results show the spatial distribution of different erosion prone areas in watershed, where management practices might be suitable to prevent soil erosion. The analysis is important for the environmental planning, because can give subsidy to the establishment of the sustainable development of the basin.
\end{abstract}

Keywords: surface processes; landuse; geographical information system; remote sensing

\section{Introdução}

Uma importante preocupação para o planejamento conservacionista é a erosão, causadora de diversos impactos ambientais que atinge a população urbana e rural, como: perda da biodiversidade, comprometimento da qualidade da água, redução da produtividade agrícola, assoreamento de rios, redução da capacidade de drenagem, inundações, entre outros.

O principal agente erosivo em ambiente tropical é a água, que intensifica sua ação quando não infiltrando no solo, seja por deficiência de cobertura vegetal ou compactação (Primavesi, 1987; Bertoni e Lombardi Neto, 1990; Merten et al., 1995). A erosão hídrica pode ser de dois tipos: laminar ou linear. A erosão laminar é gerada pelo fluxo difuso de água na superfície, provocando a dispersão de energia em múltiplos canais, que resulta na remoção progressiva e relativamente uniforme dos sedimentos dos horizontes superficiais do solo. É um dos tipos de erosão mais importantes, porém dificilmente perceptível podendo ser identificada pelo decréscimo de produção das culturas e pelo aparecimento de raízes. Em contraposição, a erosão linear concentra o escoamento da água gerando sulcos, ravinas e voçorocas.

A ação humana pode promover um aumento substancial da taxa de erosão e sedimentação pela ocupação desordenada e o manejo inadequado do solo. A remoção da vegetação natural através do desmatamento intensifica o processo erosivo podendo tornar a taxa de perda de solos superior à taxa de formação (Curi et al., 1993). Além disso, o solo submetido ao cultivo intensivo tem a sua estrutura original alterada e compactada (Panachuki, et al., 2006). A compactação do solo provoca alteração reduzindo permeabilidade e capacidade de infiltração do solo modificando a dinâmica do ciclo hidrológico e o equilíbrio ambiental. Sob este ponto de vista, solos de baixa suscetibilidade a erosão podem tornarse altamente suscetíveis à medida que o uso e o manejo se efetiva de forma inadequada. 
Avaliação multitemporal da susceptibilidade erosiva na bacia do rio Urucuia (MG) por meio da EUPS

Vários modelos têm sido elaborados e aplicados como ferramentas de avaliação nos estudos erosivos. Os modelos por serem simplificações ou abstrações da realidade buscam elaborar hipóteses e predições de um determinado sistema (Harvey,1969; Haggett \& Chorley, 1967). Cook (1936) foi um dos primeiros a formular um modelo de erosão, onde os fatores considerados foram erodibilidade do solo, erosividade da chuva e cobertura vegetal. A partir disso, foram propostas a adição de outros fatores ao modelo como: elemento topográfico (comprimento de rampa e declividade) (Zingg, 1940); práticas conservacionistas (Smith, 1941); e uso e manejo do solo (Browning \& Class, 1947).

Inicialmente denominada de Musgrave, a Equação Universal de Perdas de Solos - EUPS (Universal Soil Loss Equation - USLE) foi desenvolvida em 1954, pelo National Runoff and Soil Loss Data Center pela Agricultural Research Service em colaboração com a Universidade de Perdue (USA) e revisada por Wischmeier e Smith (1965 e 1978). A equação da EUPS (em ton/ha.ano) é o produto dos seguintes atributos [1]: (1) da erosividade da chuva (Fator R - MJ.mm/(ha.h)), (2) da erodibilidade do solo (Fator K - em ton. ha.h./ha.(MJ.mm)), (3) do comprimento de rampa (Fator L - adimensional) e do gradiente da declividade (Fator S - em \%), (4) da cobertura superficial ou uso/manejo (Fator $\mathrm{C}$ - adimensional) e, (5) das práticas conservacionistas (Fator $\mathrm{P}$ - adimensional), conforme a equação abaixo:

$$
A=R \times K \times L \times S \times C \times P
$$

Tal equação foi criada para aplicação em pequenas áreas de clima temperado, entretanto, seu uso em regiões tropicais e em escala regional é possível, principalmente, em um enfoque qualitativo a fim de discriminar áreas de maior e menor suscetibilidade à erosão (Hoyos, 2005, Stein et al., 1987, Bloise et al., 2001). Esta informação, ainda que qualitativa, fornece subsídios relevantes para a elaboração do planejamento agrícola e ambiental de bacias hidrográficas. A adequação do modelo da EUPS em ambiente computacional de um SIG permite uma otimização e resultados espaciais mais precisos.

O presente trabalho possui como objetivo qualificar áreas que são mais susceptíveis a erosão na Bacia do Rio Urucuia por meio de uma análise multitemporal da EUPS nos anos 1987 e 2007. Este enfoque temporal permitirá avaliar a progressão antrópica e suas relações com processos erosivos na área de estudo. Desta forma, este trabalho fornecerá subsídios para o planejamento territorial da Bacia do Rio Urucuia, área com intensas atividades agropastoris.

\section{2. Área de Estudo}

A Bacia do Rio Urucuia está localizada praticamente toda no estado de Minas Gerais com algumas pequenas áreas de nascentes situadas no estado de Goiás $\left(45^{\circ} 04^{\prime} 33^{\prime \prime} \mathrm{W}\right.$ a

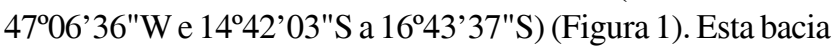
aporta ao rio São Francisco contribuindo com 10\% de sua vazão total e 18\% da carga total de sedimentos (CODEVASF, 2002).

A bacia insere-se em duas tipologias climáticas da classificação de Thornthwaite (1948): (a) tipo B2 (úmido) na porção oeste, que engloba a maior parte da bacia, de montante até as proximidades da confluência do Ribeirão Santa Cruz com o Rio Urucuia, e (b) Tipo C1 (sub-úmido seco) na porção leste da bacia até a confluência com o Rio São Francisco. O domínio climático na região Noroeste de Minas Gerais, que inclui a bacia do rio Urucuia, é o clima quente. Todos os meses do ano acusam temperatura média superior a $18^{\circ} \mathrm{C}$, sendo que a média anual é de $23^{\circ} \mathrm{C}$. O período seco é sempre quente e muito longo, de setembro a março, seguido de uma estação chuvosa que vai de abril a agosto. No vale do Urucuia, conforme dados do site da ANA (Hidroweb) as médias de precipitação são boas (com total de chuva anual variando entre $1150 \mathrm{~mm}$ e $1400 \mathrm{~mm}$ ). Os máximos verificados nesta região ocorrem nos meses de dezembro ou janeiro. Os valores mínimos de precipitação são verificados entre os meses de junho a agosto.

A região abrangida pelo Cráton do São Francisco apresenta um registro de sucessivos ciclos sedimentares desde o fim do Paleoproterozóico compreendendo diferentes unidades litoestratigráficas (Campos \& Dardenne, 1997; Martins-Neto et al., 2001; Spigolon e Alvarenga, 2002). A estratigrafia Fanerozóica é resultante do preenchimento de uma bacia intracratônica denominada de Bacia Sanfranciscana (Sgarbi, 1989). A Bacia do Rio Urucuia apresenta rochas neoproterozóicas do Grupo Paranoá, bem como uma seção fanerozóica, representadas pelos seguintes grupos: Grupo Bambuí, Grupo Areado e Grupo Urucuia.

O levantamento de solos existente na área em estudo foi realizado em escala regional (1.1.000.000) onde são descritos as seguintes classes de solo: Latossolo, Neossolo, Argissolo e Cambissolo (Brasil, 1982; EMBRAPA, 1999).

A vegetação é do Bioma Cerrado com a presença das seguintes fitofisionomias: Cerrado sentido restrito, Cerradão, Vereda, Mata Ciliar, Campo sujo e limpo. O Mapa de vegetação elaborado na escala 1:5.000.000 (IBGE, 1988) apresenta a predominância de savana (ou cerrado) natural, em especial com vegetação arbórea aberta. Há ainda a presença de Floresta estacional, que se distribui em forma de manchas nas porções Noroeste e Sudoeste da Bacia. Na bacia ocorrem extensas áreas de pastagem e de plantio provenientes da expansão da fronteira agrícola e do desenvolvimento da região. As áreas mais preservadas limitam-se, de modo geral aos locais de relevo mais escarpado. Os locais de planície e planalto apresentam intenso uso com presença de atividades agrícolas diversas. 


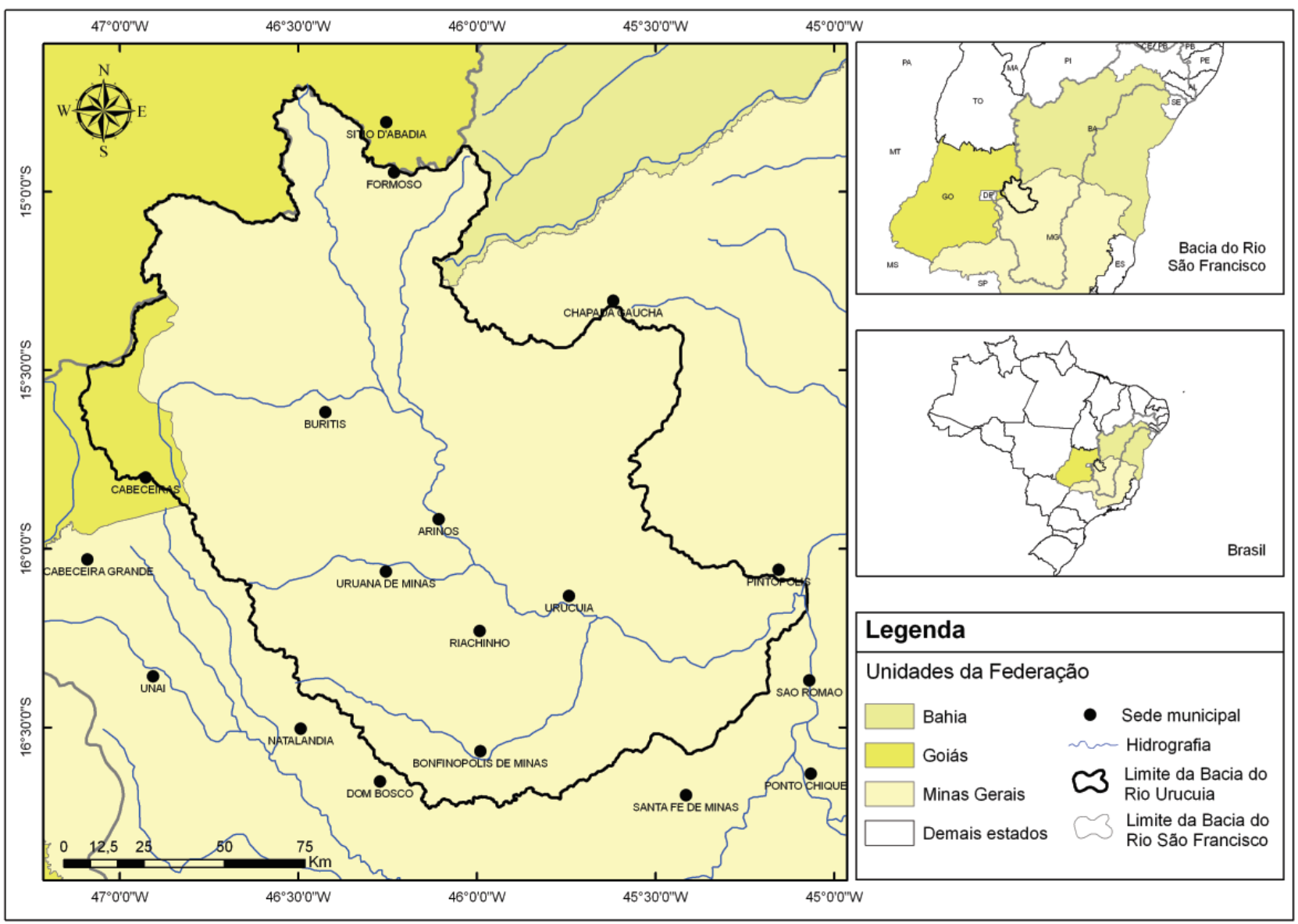

Figura1. Mapa de localização da Bacia do Rio Urucuia-MG.

\section{Metodologia}

\section{Fator Topográfico (LS)}

O comprimento de rampa (L) e a declividade $(\mathrm{S})$ podem ser extraídos de um MDT em um ambiente de SIG. A geração do MDT da área de estudo utilizou vinte cartas topográficas na escala 1:100.000 em meio digital cedidas pela CODEVASF (Companhia para o Desenvolvimento do Vale do São Francisco e Parnaíba). Inicialmente os dados das cartas topográficas foram submetidos às seguintes correções: (a) curvas de nível (conexão das curvas, averiguação das cotas e junção das curvas fragmentadas); (b) pontos cotados (averiguação das cotas); (c) drenagens (verificações dos nós, junção de vetores fragmentados e correção da direção de fluxo); e (d) lagos (averiguação de polígonos). A interpolação dos dados foi realizada pelo método Topogrid, implementado no programa Arcinfo (Hutchinson, 1989). Este procedimento de interpolação utiliza o método de diferenças finitas conjugando tanto o esforço de manter as características hidrográficas (drenagens, lagos e direção de fluxo) como a remoção de dados espúrios relativos a pontos de depressões ou de elevações (Hutchinson, 1989). Este procedimento possui a eficiência computacional dos métodos de interpolação local (método IDW) e a continuidade da superfície proporcionada pelos interpoladores globais (interpolador Kriging) (Guimarães, 2000). O Topogrid possui melhores resultados quando comparado com outros métodos de interpolação como: INTERCON (do software IDRISI), o Inverso do Quadrado da Distância (IQD), Kriging e Krigeagem MultiDirecional (Fernandes \& Menezes, 2005). O MDT foi confeccionado com resolução espacial de 35 metros (Figura 2).

O comprimento de rampa (Fator L) está estreitamente correlacionado a capacidade de remoção, de transporte e de sedimentação das partículas do solo pelo escoamento superficial. O Fator L pode ser caracterizado como sendo à distância do ponto de origem do caimento da água até o ponto em que ela decresce, propiciando o início de uma sedimentação em rupturas de uma vertente junto a vales, ou quando vai de encontro a um canal definido (Wischmeier \& Smith, 1978). Em ambiente SIG, o comprimento de rampa pode ser proveniente do atributo de terreno área de contribuição, a qual permite determinar, com maior precisão, os processos erosivos 


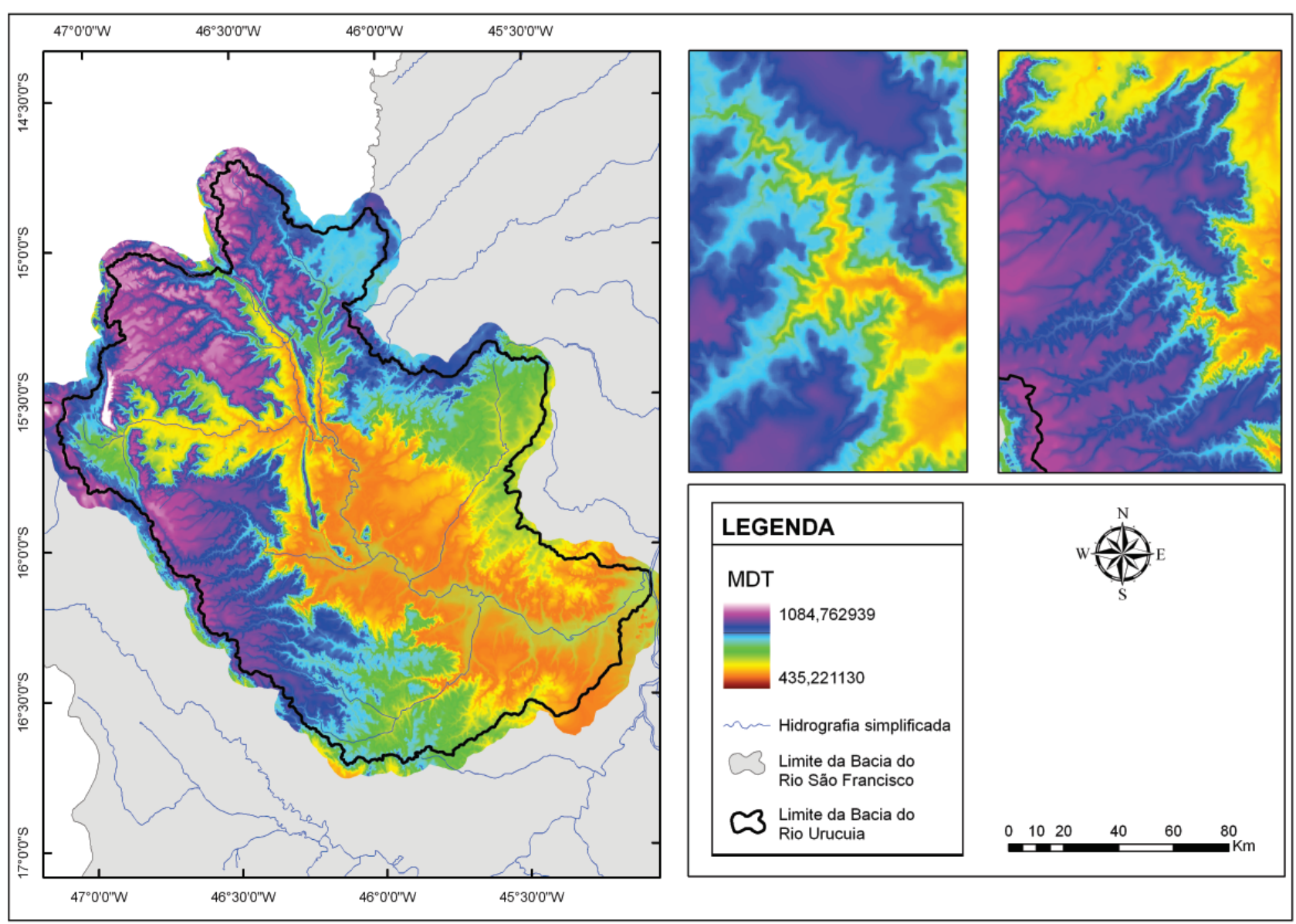

Figura 2. Modelo Digital do Terreno gerado pelo método de interpolação Topogrid.

advindos do fluxo laminar sobre declives (Moore \& Bruch, 1986). Desmet \& Govers (1996) aprimoraram o cálculo do fator L considerando as equações de Foster \& Wischmeier (1974):

$$
L_{i j}=\frac{\left[\left(A_{i j-i n}+D^{2}\right)^{m+1}-\left(A_{i j-i-i}\right)^{n+1}\right.}{D^{m+2} \cdot x_{i j}(22,13)^{m}}
$$

Onde a variável " $\mathrm{L}_{\mathrm{i}, \mathrm{j}}$ " é o fator de comprimento de vertente de uma célula com coordenadas $(\mathrm{i}, \mathrm{j})$; “ $\mathrm{A}_{\mathrm{i}, \mathrm{j} \text {-in }}$ " é a área de contribuição da célula em coordenadas $(\mathrm{i}, \mathrm{j})\left(\mathrm{m}^{2}\right)$; " $\mathrm{D}$ " é o tamanho da célula; " $x$ " é o coeficiente função do aspecto para grade de célula em coordenadas (i,j); e "m" é o coeficiente função da declividade para grade de célula com coordenada (i,j).

Na estimativa da área de contribuição foi utilizado o método D-infinito proposto por Tarboton (1997), pois segundo Farinasso et al., (2006) apresenta melhores resultados na estimativa do fator L que o método D8 proposto por O’Calaghan \& Mark, (1984).

A declividade (S) do terreno proporciona a aceleração da água e o aumento do potencial erosivo. Conforme Wischmeier e Smith (1978), o fator declividade (S) é calculado pela equação com a variável declividade média da vertente em porcentagem (s):

$$
S=0,00654 s^{2}+0,0456 s+0,065
$$

Para cálculo do fator LS aplica-se a equação de Bertoni e Lombardi Neto (1990), que considera o comprimento de rampa em metros (L) e a declividade em porcentagem $(\mathrm{S})$ :

$$
L S=0,00984 \times L^{0,63} \times S^{1,12}
$$

\section{Fator Erosividade (R)}

$\mathrm{O}$ fator R (MJ.mm/ha.h.ano) corresponde à capacidade erosiva da chuva em contato direto com o solo. Este fator depende das características físicas das chuvas, tais como: intensidade, duração, distribuição e tamanho das gotas (Wischmeier \& Smith, 1958). Lombardi Neto \& Moldenhauer (1980) propõem para o município de Campinas o Índice de Erosividade (EI) baseado na média do total mensal (r) e anual (p) de precipitação em milímetros de uma determinada estação pluviométrica [5].

$$
E I=67,355\left(r^{r^{2}}{ }_{P}\right)^{0,85}
$$


Conhecendo-se o Índice de Erosividade para cada estação pluviométrica aplica-se o cálculo do Fator R pela equação de Wischmeier \& Smith (1978) considerando a energia cinética da chuva $(\mathrm{EI})$ :

$$
R=\sum_{j=1}^{12} E I_{j}
$$

Para uma estimativa confiável do Fator R é necessário uma análise temporal relativo a um período de 10 a 20 anos (Wischmeier \& Smith, 1978). No presente trabalho foram utilizadas dezessete estações que tinham uma consistente base de dados, relativa a uma série histórica de 20 anos (1987 até 2007) e boa distribuição espacial.

\section{Fator Erodibilidade (K)}

O Fator K reflete a suscetibilidade à erosão ou a falta de capacidade de resistir aos processos erosivos para um determinado tipo de solo (Wischmeier \& Smith, 1978; Vilar \& Prandi, 1993). Tal fator depende de vários atributos como: textura, teor de matéria orgânica, estrutura e permeabilidade (Resende, 1985). Para a determinação da erodibilidade do solo vários métodos foram elaborados (Wischmeier et al., 1971; Lombardi Neto \& Bertoni, 1975; Denardin, 1990).

Nesta pesquisa foi utilizada a formulação Chaves (1994) que desenvolveu uma equação para determinação do Fator K para a Bacia do Rio São Francisco. Este método leva em consideração a concentração de silte (SIL), carbono orgânico (CO), porcentagem de óxido de alumínio (OAL), porcentagem de óxido de ferro (OFE) e porcentagem de óxido de silício (OSI), sendo todos os óxidos extraíveis por ácido sulfúrico.

$$
\begin{aligned}
K= & 2,47 \times 10^{-3}(S I L)-5,23 \times 10^{-3}(O A L)+ \\
& +8,89 \times 10^{-3}(C O)^{2}+1,15 \times 10-2(O F E)^{-1}+ \\
& +1,42 \times 10^{-4}\left(O S I+O S I^{2}\right)-1,89 \times 10^{-2}\left[\frac{O S I}{(O F E+O A L)}\right]^{2}
\end{aligned}
$$

\section{Fator Uso, Manejo e Práticas Conservacionistas (CP)}

Bertoni e Lombardi Neto (1990) conceituaram os Fatores $\mathrm{C}$ e $\mathrm{P}$ de forma dissociada. O Fator $\mathrm{C}$ (uso e manejo) pode ser definido como a relação esperada entre as perdas do solo de uma área cultivada, segundo um manejo qualquer, e as perdas correspondentes de um solo na mesma área, mantendo o solo descoberto e cultivado. O Fator P (prática conservacionista), por sua vez, é caracterizado como a relação entre a intensidade esperada de perdas com determinada prática conservacionista e aquelas quando a cultura está plantada no sentido do declive (morro abaixo). O Fator CP de forma conjunta é definido como a relação entre a perda de solo esperada das áreas com cultivos e vegetação e as áreas descobertas.
Para a Bacia do Rio Urucuia foi realizada uma análise da evolução do fator $\mathrm{CP}$ em relação a dois períodos. $\mathrm{O}$ fator $\mathrm{CP}$ foi obtido pelo mapa de uso da terra extraído da imagem de satélite TM-Landsat 5 referentes às datas de 09/08/1987 e 08/ 09/2007. A metodologia adotada pode ser subdividida nas seguintes etapas: (a) classificação da imagem pelo método Iterative Self-Organizing Data Analysis Technique (ISODATA); (b) aferição de campo; e (c) ajuste manual.

O classificador ISODATA é um método não supervisionado que permite uma análise exploratória dos dados sem a intervenção do usuário (Ball \& Hall 1967). Este método está no âmbito dos classificadores por análise de grupos, sendo cada vez mais empregada como uma forte ferramenta na investigação científica, contribuindo significativamente para uma análise exploratória dos sistemas existentes. A análise de grupos tem como propósito particionar um conjunto de $\mathrm{N}$ entidades, em subconjuntos distintos e não vazios, que sejam tão homogêneos quanto possível (Sampaio, 1990). A classificação dos grupos é definida por intermédio de uma medida de similaridade ou dissimilaridade entre os parâmetros, como por exemplo, o da distância Euclidiana. No final do processo objetiva-se definir grupos ou clusters que sejam pertinentes e decorrentes naturais da própria estruturação dos dados. O ISODATAé um método não hierárquico que seleciona primeiramente os centros para os agrupamentos denominados sementes e a partir de uma distância pré-determinada agrupa os elementos em sua volta, sendo que o número de classes não é definido anteriormente. Este método estatístico favorece a formulação de hipóteses sobre a estrutura interna dos dados. As classificações realizadas foram aferidas em trabalho de campo que permitiu proceder um ajuste manual no intuito de salientar as classes de interesse e diminuir o número de polígonos gerados.

A partir das classes de uso e cobertura da terra podemse definir índices do fator CP. Na Bacia do Rio Urucuia são adequados os índices propostos por Stein et al.,(1987) (Tabela 1).

A suscetibilidade a erosão é obtida para as duas datas trabalhadas (1987 e 2007) pela multiplicação dos fatores da EUPS (LS, R, Ke CP).

Tabela 1. Classes de C e P adotadas para a Bacia do Rio Urucuia$M G$

\begin{tabular}{l|c}
\hline \multicolumn{1}{c|}{ Classe } & Fator CP \\
\hline Corpos d água & 0,0 \\
\hline Área Urbana & 0,0 \\
\hline Áreas Inundáveis ou alagadas & 0,0 \\
\hline Mata Ciliar e Cerradão & 0,00004 \\
\hline Cerrado & 0,00007 \\
\hline Área Rural de Uso Diversificado & 0,2 \\
\hline
\end{tabular}




\section{Resultados}

\section{Resultados dos Fatores Físicos (LS, R, K)}

O Fator LS gerado demonstra uma grande extensão de áreas com baixos valores nas áreas planas das chapadas e de planícies, sobretudo nas proximidades da confluência do canal principal com o Rio São Francisco (Figura 3). A exceção a esse padrão limita-se às bordas de chapadas, onde o alto grau de declividade configura uma mudança abrupta não só no padrão de perda de solo como também na paisagem. Desta forma, os locais de mais altos valores estão associados aos canais fluviais em declividade acentuada, que configura um relevo encaixado.
No cálculo do fator $\mathrm{R}$ foram utilizadas dezessete estações que apresentam médias anuais em torno de 870 a 1.414 mm (Tabela 2). A estação Formosa localizada além do limite da Bacia do Rio Urucuia possui a maior média anual devido à existência de intensas chuvas orográficas provocadas pelas cristas de Unaí. Pelo mesmo motivo tem-se elevada taxa anual pluviométrica na estação Sítio D’Abadia que se localiza fora da bacia do Rio Urucuia próximo a um conjunto de serras. Em contrapartida a menor taxa anual foi encontrada na estação Serra das Araras na porção sudeste da bacia, seguido da estação Miravânia, ambas fora dos limites da bacia. O Fator Erosividade da chuva (R) pode ser dividido em quatro classes: (a) 6.600-7100 MJ.mm/ha.h.ano,

Tabela 2. Estações pluviométricas utilizadas para a análise

\begin{tabular}{|c|c|c|c|c|c|}
\hline Estação & Coordenadas & Município & Estado & MA & $\mathbf{R}$ \\
\hline Sítio D Abadia & $\begin{array}{l}14^{\circ} 4814 \mathrm{~S} \\
46^{\circ} 1512 \mathrm{~W}\end{array}$ & Sítio D Abadia & GO & 1217,6 & 7135,0 \\
\hline Serra das Araras & $\begin{array}{l}15^{\circ} 3008 \mathrm{~S} \\
45^{\circ} 2324 \mathrm{~W}\end{array}$ & Chapada Gaúcha & MG & 870,6 & 9256,9 \\
\hline Arinos (Montante) & $\begin{array}{l}15^{\circ} 5528 \mathrm{~S} \\
46^{\circ} 0635 \mathrm{~W}\end{array}$ & Arinos & MG & 1137,3 & 7685,5 \\
\hline Cabeceiras & $\begin{array}{l}15^{\circ} 4803 \mathrm{~S} \\
46^{\circ} 5529 \mathrm{~W}\end{array}$ & Cabeceiras & GO & 1300,0 & 7816,5 \\
\hline Faz. Carvalho & $\begin{array}{l}15^{\circ} 3118 \mathrm{~S} \\
46^{\circ} 1659 \mathrm{~W}\end{array}$ & Buritis & MG & 1165,4 & 7617,6 \\
\hline Faz. Conceição & $\begin{array}{l}16^{\circ} 2543 \mathrm{~S} \\
45^{\circ} 4432 \mathrm{~W}\end{array}$ & Riachinho & MG & 1122,3 & 7295,4 \\
\hline São Romão & $\begin{array}{l}16^{\circ} 2218 \mathrm{~S} \\
45^{\circ} 0458 \mathrm{~W}\end{array}$ & São Romão & MG & 1027,9 & 6744,0 \\
\hline Vila Urucuia & $\begin{array}{l}16^{\circ} 1801 \mathrm{~S} \\
45^{\circ} 4422 \mathrm{~W}\end{array}$ & Riachinho & MG & 1043,2 & 6629,8 \\
\hline Faz. Limeira & $\begin{array}{l}16^{\circ} 1222 \mathrm{~S} \\
47^{\circ} 1329 \mathrm{~W}\end{array}$ & Cabeceira Grande & MG & 1089,4 & 9377,3 \\
\hline Faz. O Resfriado & $\begin{array}{l}16^{\circ} 3042 \mathrm{~S} \\
46^{\circ} 3944 \mathrm{~W}\end{array}$ & Unaí & MG & 1060,2 & 8435,9 \\
\hline Formosa & $\begin{array}{l}15^{\circ} 3156 \mathrm{~S} \\
47^{\circ} 2034 \mathrm{~W}\end{array}$ & Formosa & GO & 1414,1 & 8073,1 \\
\hline Porto dos Poções & $\begin{array}{l}16^{\circ} 4945 \mathrm{~S} \\
46^{\circ} 1922 \mathrm{~W}\end{array}$ & Dom Bosco & MG & 1139,2 & 7178,2 \\
\hline Rio Preto & $\begin{array}{l}15^{\circ} 4756 \mathrm{~S} \\
47^{\circ} 2704 \mathrm{~W}\end{array}$ & Brasília & DF & 1212,1 & 7566,5 \\
\hline Buritis (Jusante) & $\begin{array}{l}15^{\circ} 3658 \mathrm{~S} \\
46^{\circ} 2449 \mathrm{~W}\end{array}$ & Buritis & MG & 1255,2 & 7459,98 \\
\hline Gaúchos & $\begin{array}{l}15^{\circ} 1742 \mathrm{~S} \\
45^{\circ} 3736 \mathrm{~W}\end{array}$ & Formoso & MG & 1242,4 & 7351,73 \\
\hline Cajueiro & $\begin{array}{l}14^{\circ} 5010 \mathrm{~S} \\
45^{\circ} 1024 \mathrm{~W}\end{array}$ & Bonito de Minas & MG & 1140,3 & 7114,20 \\
\hline Miravânia & $\begin{array}{l}15^{\circ} 3658 \mathrm{~S} \\
46^{\circ} 2449 \mathrm{~W}\end{array}$ & Miravânia & MG & 990,8 & 5844,58 \\
\hline
\end{tabular}




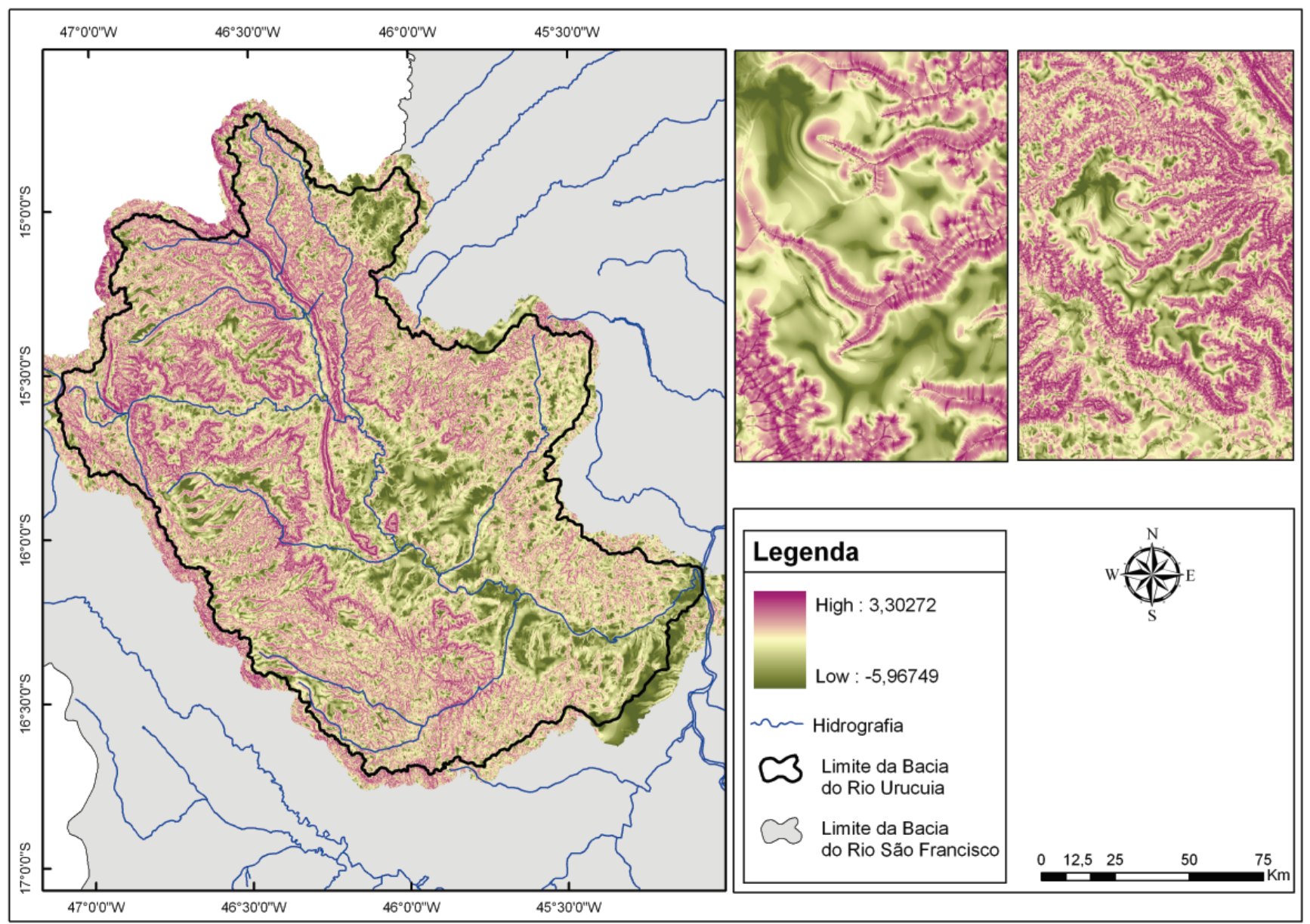

Figura 3. Mapa dos Fatores L e S gerado pelo algoritmo D infinito.

encontrada na planície sudeste da bacia; (b) 7200-7400 MJ.mm/ ha.h.ano; (c) 7500-7700 MJ.mm/ha.h.ano; e (d) 7800-8200 MJ.mm/ha.h.ano situado no oeste da bacia (Figura 4).

O Fator K foi obtido por meio da edição do mapeamento de Chaves (1994). O mapa gerado foi dividido em classes de interpretação, conforme proposto por Carvalho (1994) (Tabela 3). Como resultado o mapa de erodibilidade demonstra o seguinte padrão: (a) altas erodibilidades estão associadas, principalmente aos Neossolos Flúvicos e Cambisolos. Esta classe compreende uma área de 5.594,26 km², equivalendo a aproximadamente $23 \%$ da área total da bacia. (b) As médias erodibilidades se concentram, especialmente, sobre os solos do tipo Latossolo Vermelho Amarelo, Neossolo Quartzarênico Hidromórfico, Neossolos Litólicos, Neossolo Regolítico, Argissolo Vermelho Amarelo e Argissolo Vermelho Distrófico. Distribui-se em uma área percentual de 58,53\% (14.357,45 km²). (c) As baixas erodibilidades estão nos Neossolos Quartzarênicos profundos, Latossolo Vermelho Escuro e Solos Hidromórficos (Figura 5).

\section{Resultados dos Fatores Antrópicos (CP)}

Os mapas referentes ao uso de solo em 1987 e em 2007 são apresentados nas Figuras 6 e 7. As classes de uso e cobertura vegetal do ano de 1987 apresentam 76,28\% da área como ambiente natural (Corpos D’água, Áreas Inundáveis, Mata Ciliar/Cerradão e Cerrado), enquanto a antropizada corresponde aos 23,72\% restantes (área urbana e área rural de uso diversificado). No ano de 2007 observa-se um aumento da classe de uso agrícola que se estende continuamente nas chapadas e planície, atingindo inclusive áreas de relevo acidentado, ocupando $41,45 \%$. Nota-se pelas imagens Landsat, a presença de plantio em curva de nível em locais com declividade baixa a média.

A Tabela 3 demonstra que no período de 20 anos houve uma relevante mudança no padrão de uso do solo com implicações na susceptibilidade erosiva. Desta forma, o índice relativo ao Fator CP para o ano de 2007 demonstra um aumento da fragilidade ambiental em relação a 1987, devido ao avanço da fronteira agrícola. 


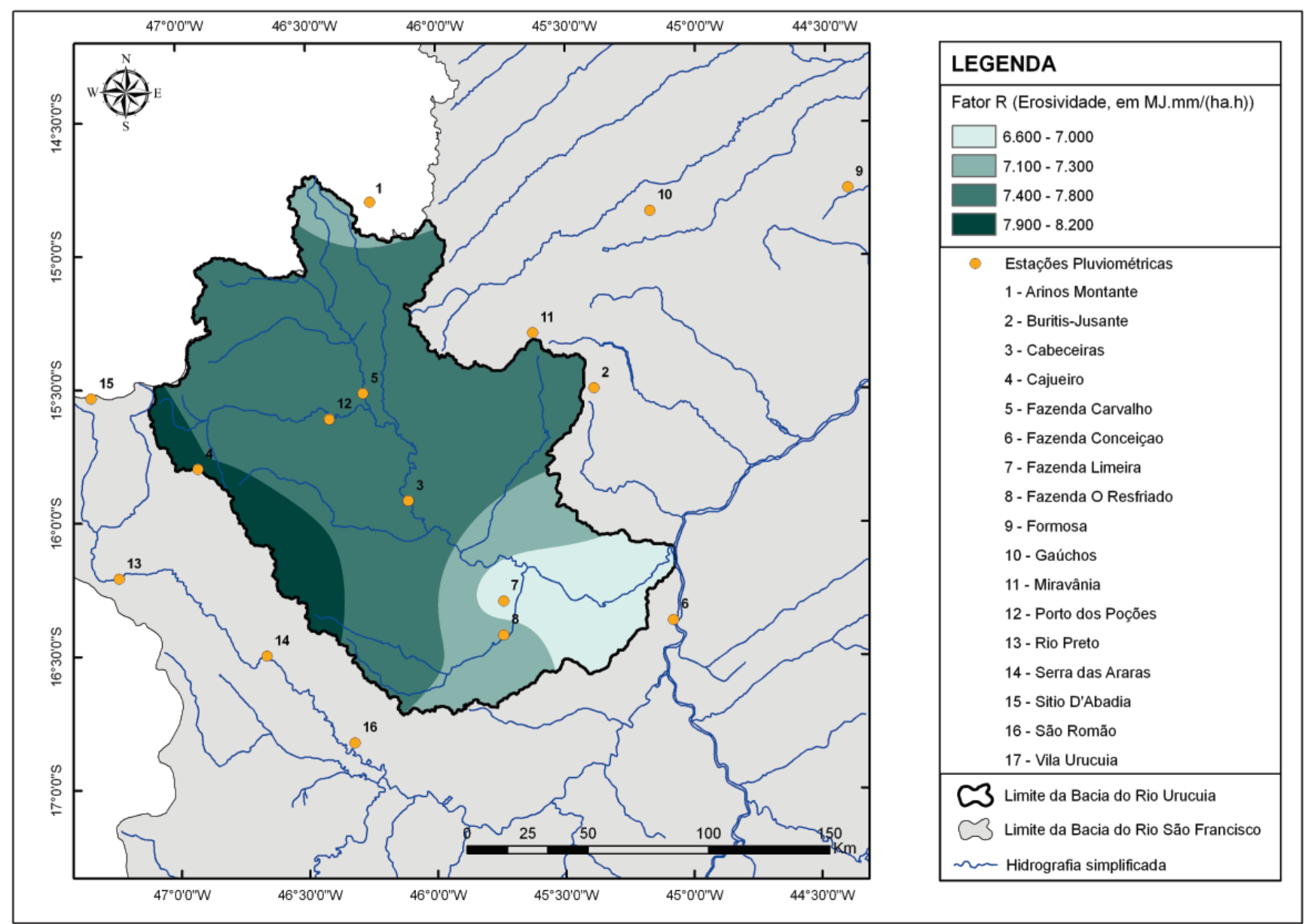

Figura 4. Mapa do Fator R (Erosividade) para a Bacia do Rio Urucuia (MG).

\section{Resultado da EUPS}

Para calcular a Erosão Atual é multiplicado cada atributo da EUPS, Fatores LS, R, K e CP. Para interpretar os valores gerados a partir deste cruzamento, Carvalho (1994) organizou classes de interpretação que vão desde nula a muito forte perda de solo (Tabela 4), tais classes dão um viés qualitativo a analise da erosão atual.

O mapa da EUPS em 1987 apresenta uma predominância da classe Nula a Moderada $(81,84 \%)$, isto decorre da combinação entre os fatores relativos ao meio físico, que dão à área a propriedade de serem fracamente erodíveis, e da grande extensão de áreas com vegetação natural (Figura 8). A classe de áreas de uso agrícola diversificado limita-se a manchas esparsas e descontínuas

Para o ano de 2007 o mapa de erosão ainda demonstra uma predominância da classe Nula a Moderada apesar de ter uma queda acentuada $(68,87 \%$ ) (Figura 9). Em seguida, em semelhantes proporções têm-se as classes Média e Média a
Forte (respectivamente 15,8\% e 11,36\%). Em baixas proporções estão à classe Forte $(3,75 \%)$ e Muito Forte $(0,22 \%)$.

A partir da comparação dos mapas de Erosão de 1987 e de 2007 é possível perceber uma diminuição da classe Nula a moderada e conseqüente aumento das demais classes. Em 2007 a fragilidade ambiental se acentua visto que o avanço das áreas destinadas a uso rural configura-se como elemento principal do aumento da susceptibilidade erosiva (Figura 10). Os Mapas de Erosão Atual configura-se como uma síntese de todos os elementos da EUPS, porém é notável a forte influência do Fator CP.

\section{Conclusão}

Entre os anos de 1987 e 2007 a mudança no padrão de uso do solo é perceptível, o aumento de áreas destinadas a uso agrícola diverso traz consigo a diminuição de áreas de vegetação preservada. Porém, a área apresenta ainda vários locais potenciais ao uso agrícola (com declividade baixa a 
Mata, C.L. et al.

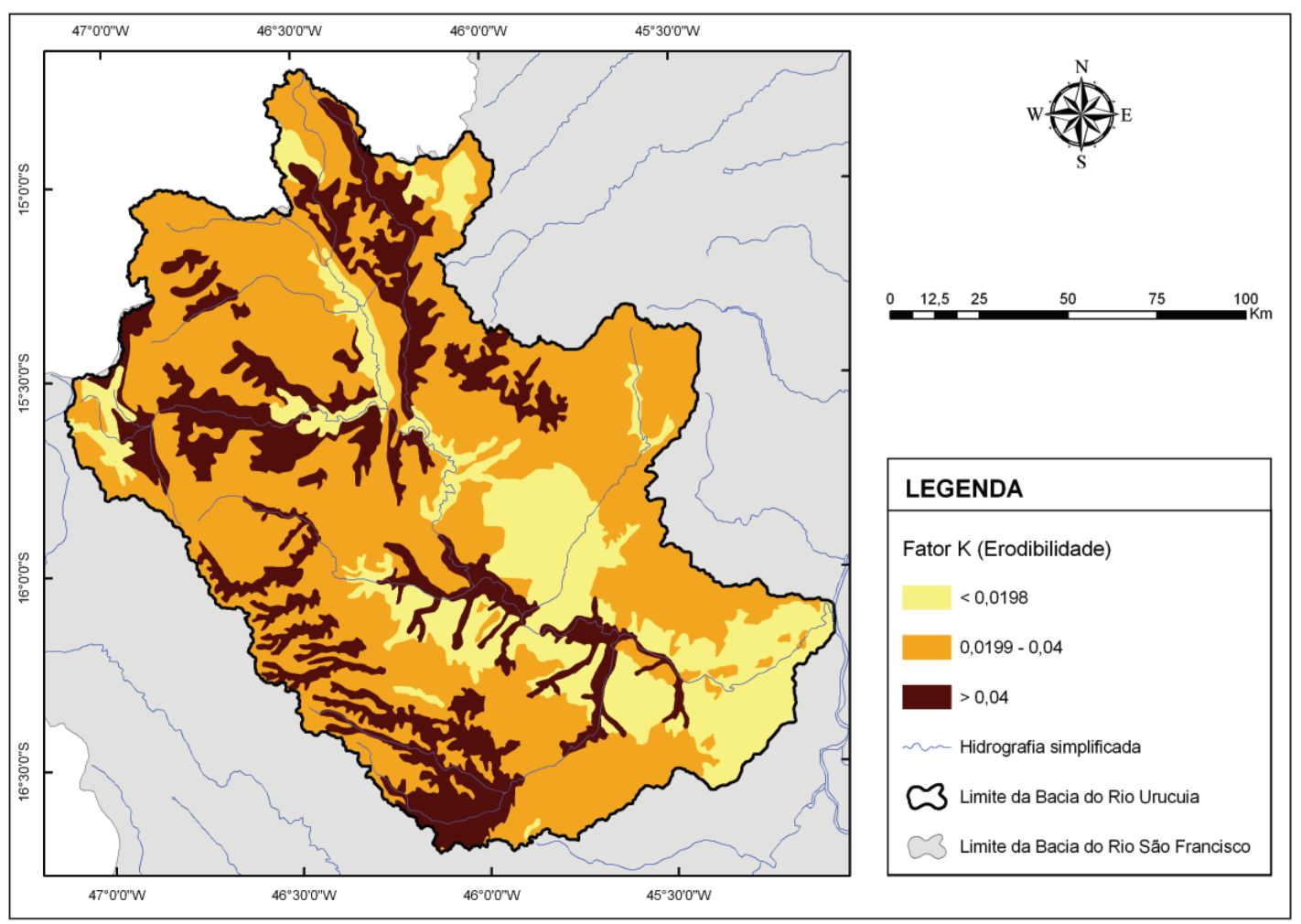

Figura 5. Mapa do Fator K da Bacia do Rio Urucuia-MG.

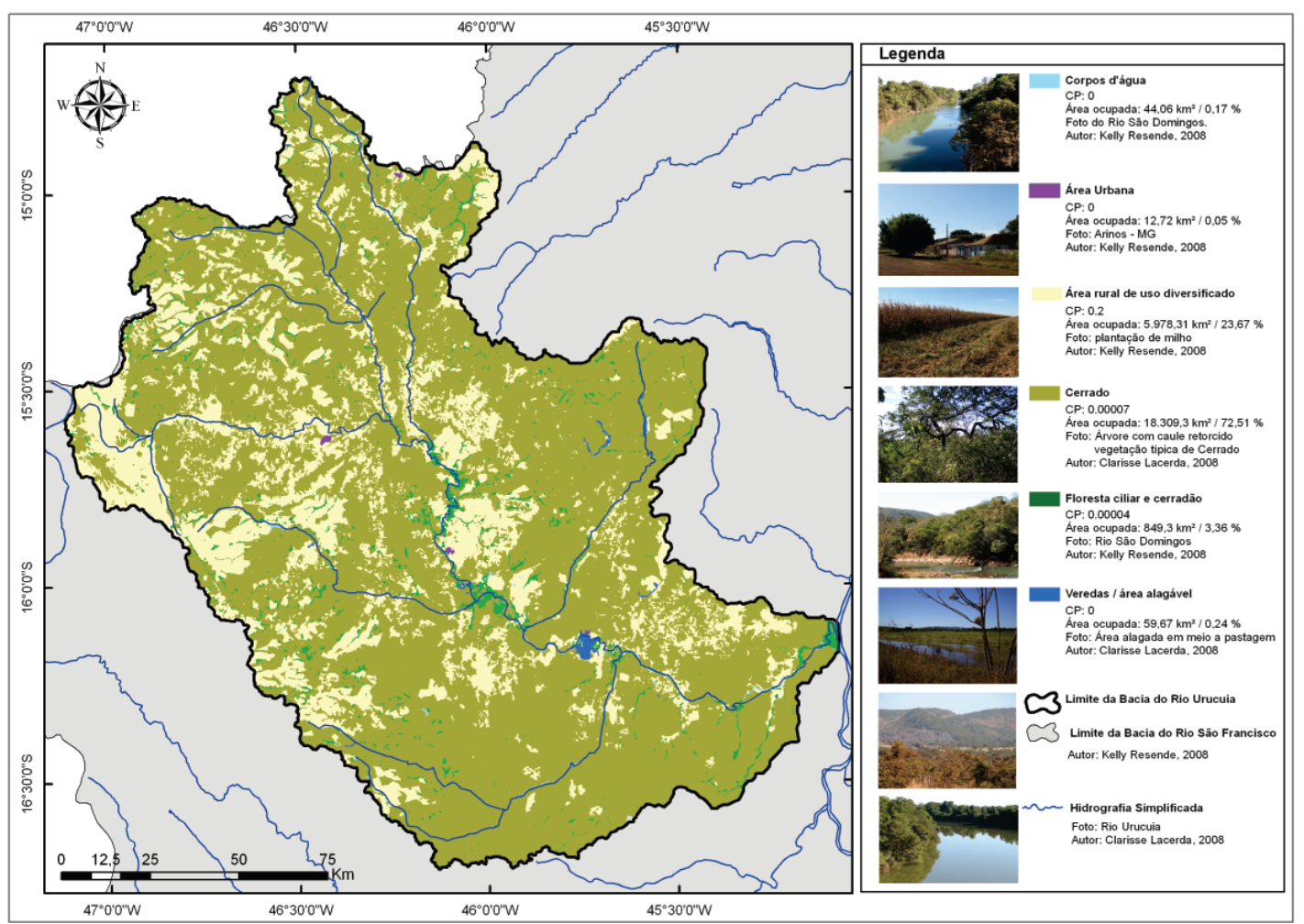

Figura 6. Mapa de uso do solo de 1987 da Bacia do Rio Urucuia-MG. 
Avaliação multitemporal da susceptibilidade erosiva na bacia do rio Urucuia (MG) por meio da EUPS

Tabela 3. Comparativo dos Fatores Ce P para a Bacia do Rio Urucuia (1987 e 2007).

\begin{tabular}{l|c|c|c|c|c}
\hline \multicolumn{1}{c|}{ ANO DE REFERÊNCIA } & \multicolumn{2}{c|}{1987} & \multicolumn{2}{c}{2007} \\
\hline \multicolumn{1}{c|}{ CLASSE } & FATOR CP & ÁREA $\left(\mathrm{Km}^{2}\right)$ & ÁREA (\%) & ÁREA $\left(\mathrm{Km}^{2}\right)$ & ÁREA (\%) \\
\hline Corpos d água & 0,0 & 44,06 & 0,17 & 36,29 & 0,14 \\
\hline Área Urbana & 0,0 & 12,72 & 0,05 & 14,76 & 0,06 \\
\hline Áreas Inundáveis ou alagadas & 0,0 & 59,67 & 0,24 & 129,06 & 0,51 \\
\hline Mata Ciliar e Cerradão & 0,00004 & 849,30 & 3,36 & $1.054,58$ & 4,16 \\
\hline Cerrado & 0,00007 & $18.309,30$ & 72,51 & $13.584,43$ & 53,6 \\
\hline Área Rural de Uso Diversificado & 0,2 & $5.978,31$ & 23,67 & $10.507,59$ & 41,45 \\
\hline
\end{tabular}

Tabela 4. Comparativo da perda de solo para a Bacia do Rio Urucuia entre 1987 e 2007 (adaptado de Carvalho, 1994).

\begin{tabular}{l|l|l|l|l|l}
\hline $\begin{array}{c}\text { TAXAS DE PERDA DE SOLO } \\
\text { ton/ha.ano) }\end{array}$ & $\begin{array}{c}\text { CLASSES DE } \\
\text { INTERPRETAÇÃo }\end{array}$ & $\begin{array}{c}\text { ÁREA }\left(\mathbf{K m}^{\mathbf{2}}\right) \\
\mathbf{1 9 8 7}\end{array}$ & $\begin{array}{c}\text { ÁREA (\%) } \\
\mathbf{1 9 8 7}\end{array}$ & $\begin{array}{c}\text { ÁREA }\left(\mathrm{Km}^{2}\right) \\
\mathbf{2 0 0 7}\end{array}$ & $\begin{array}{c}\text { ÁREA (\%) } \\
\mathbf{2 0 0 7}\end{array}$ \\
\hline$<15$ & Nula a moderada & $20.635,91$ & 81,84 & $16.669,41$ & 68,87 \\
\hline $15-50$ & Média & $2.338,31$ & 9,27 & $3.177,88$ & 15,8 \\
\hline $50-120$ & Média a forte & $1.587,80$ & 6,3 & $3.281,47$ & 11,36 \\
\hline $120-200$ & Forte & 615,30 & 2,44 & $1.438,34$ & 3,75 \\
\hline$>200$ & Muito forte & 37,39 & 0,15 & 647,67 & 0,22 \\
\hline
\end{tabular}

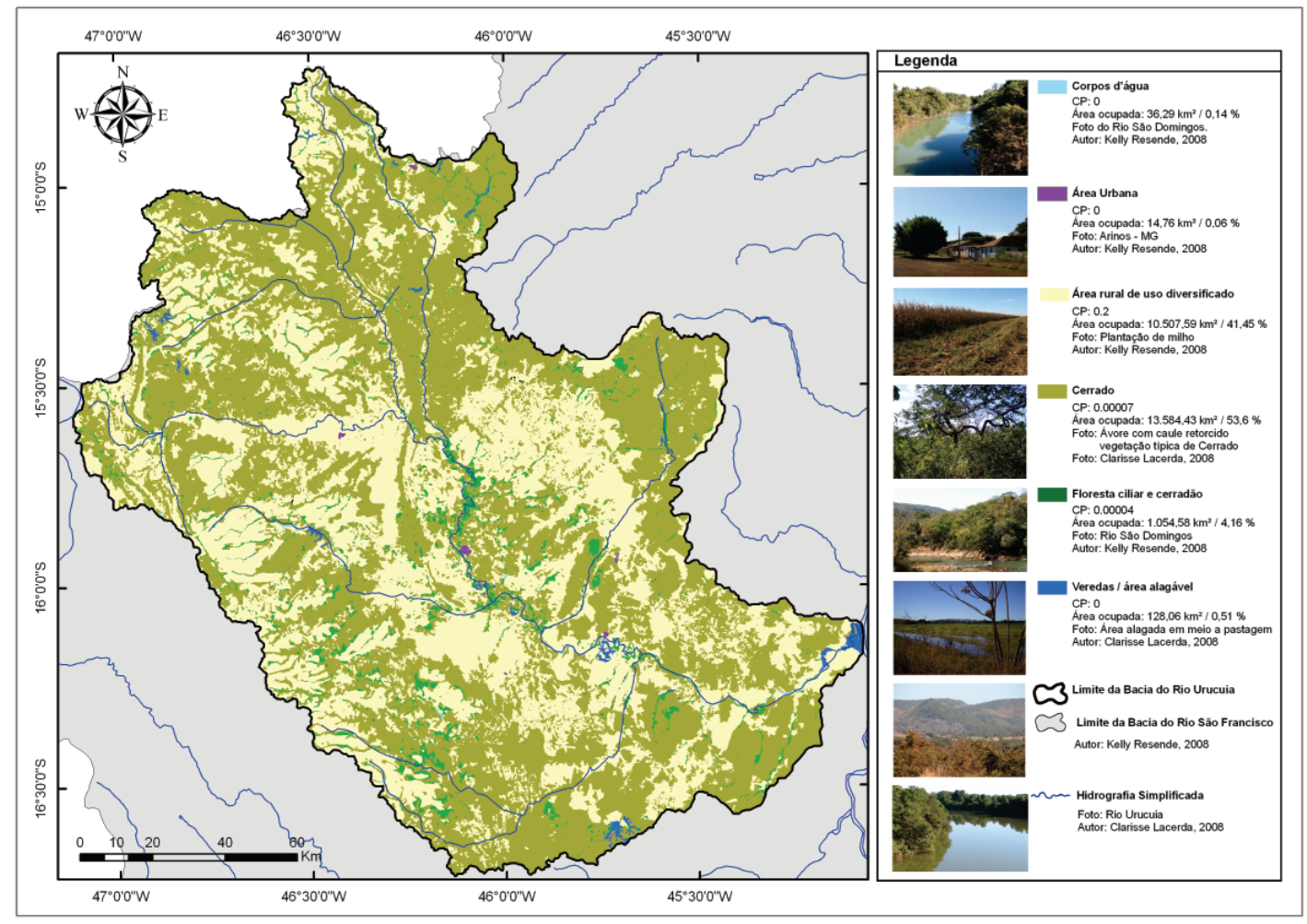

Figura 7. Mapa de uso do solo de 2007. Bacia do Rio Urucuia-MG. 
Mata, C.L. et al.

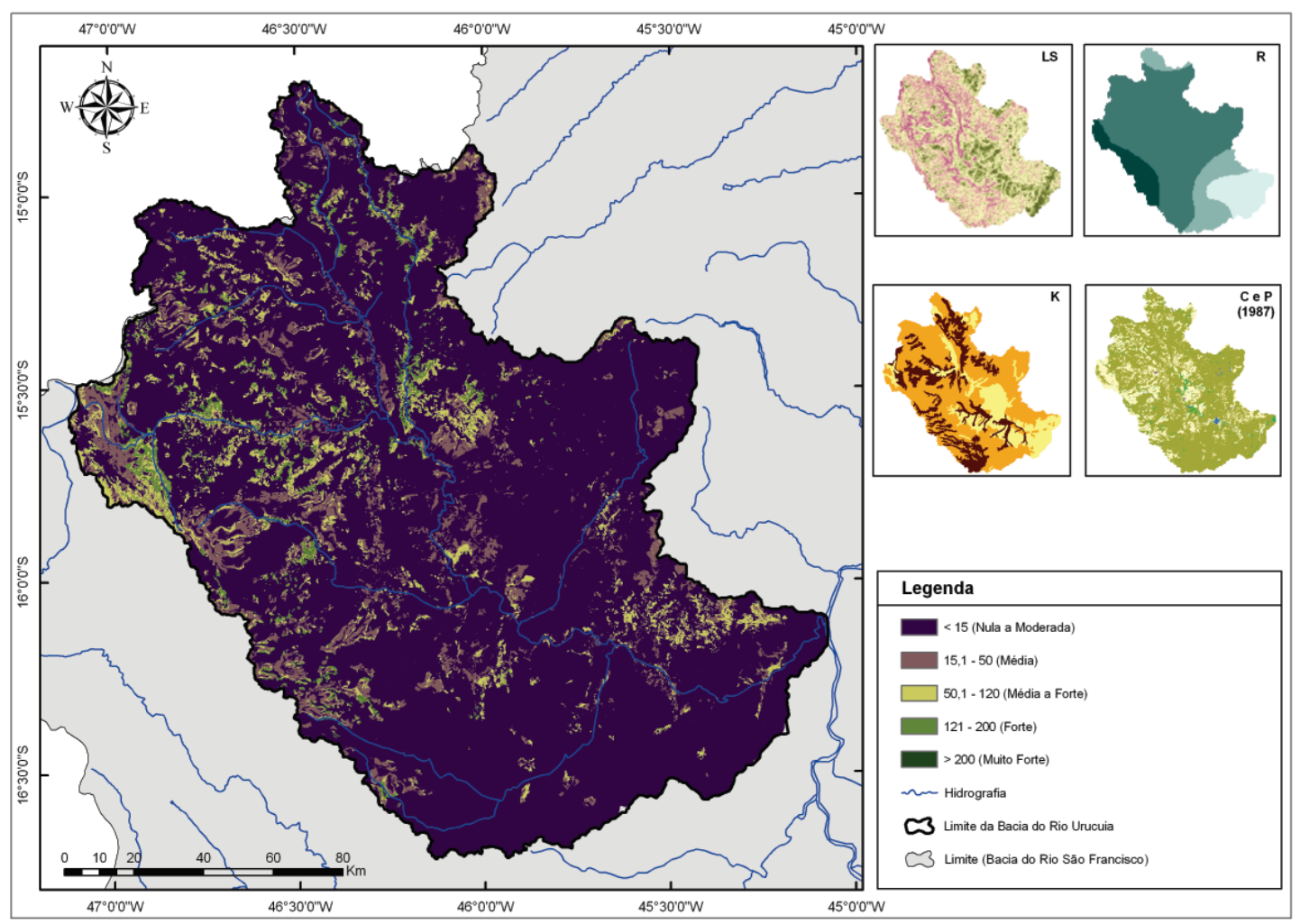

Figura 8. Mapa de Erosão Atual (1987).

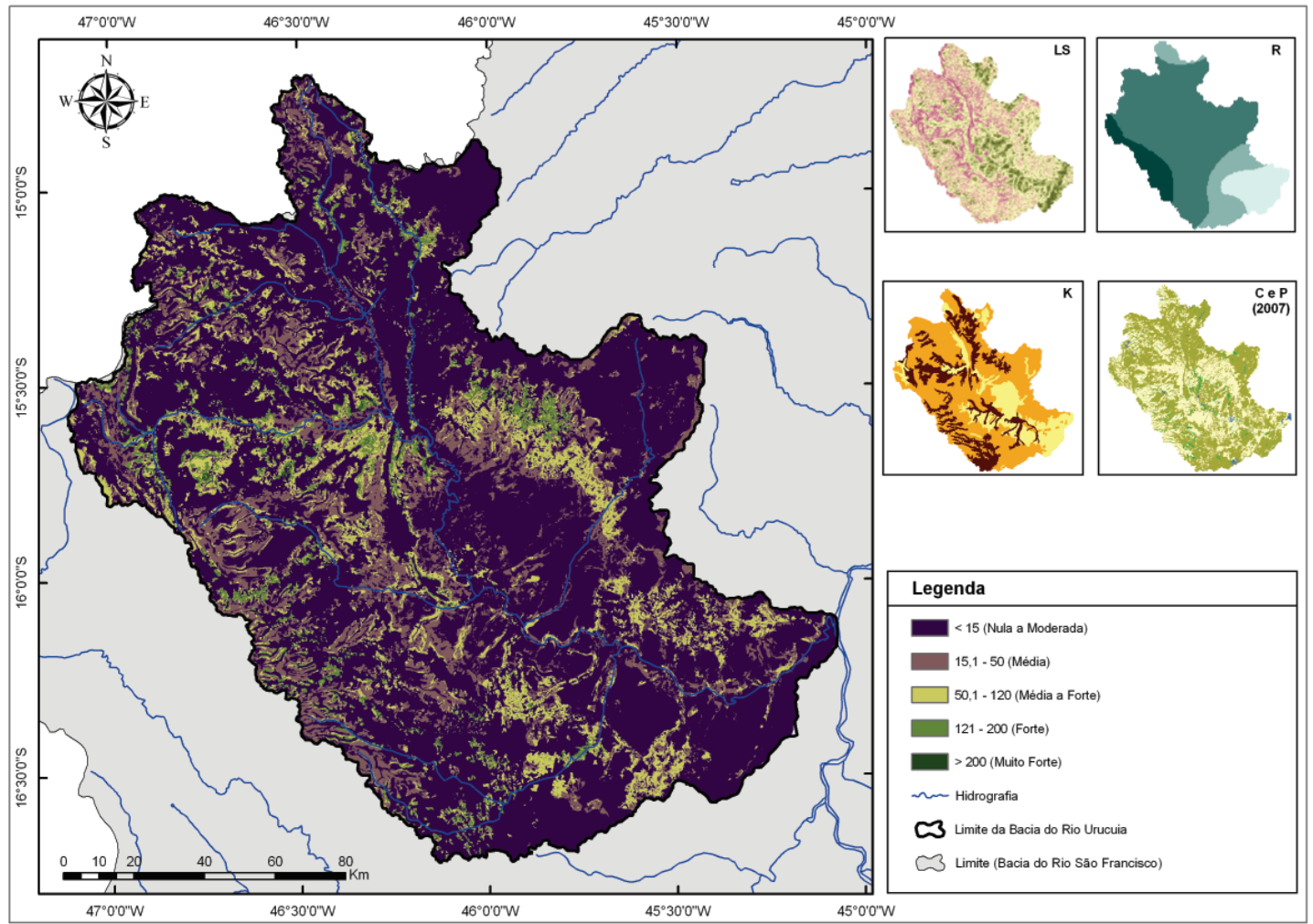

Figura 9. Mapa de Erosão Atual (2007). 


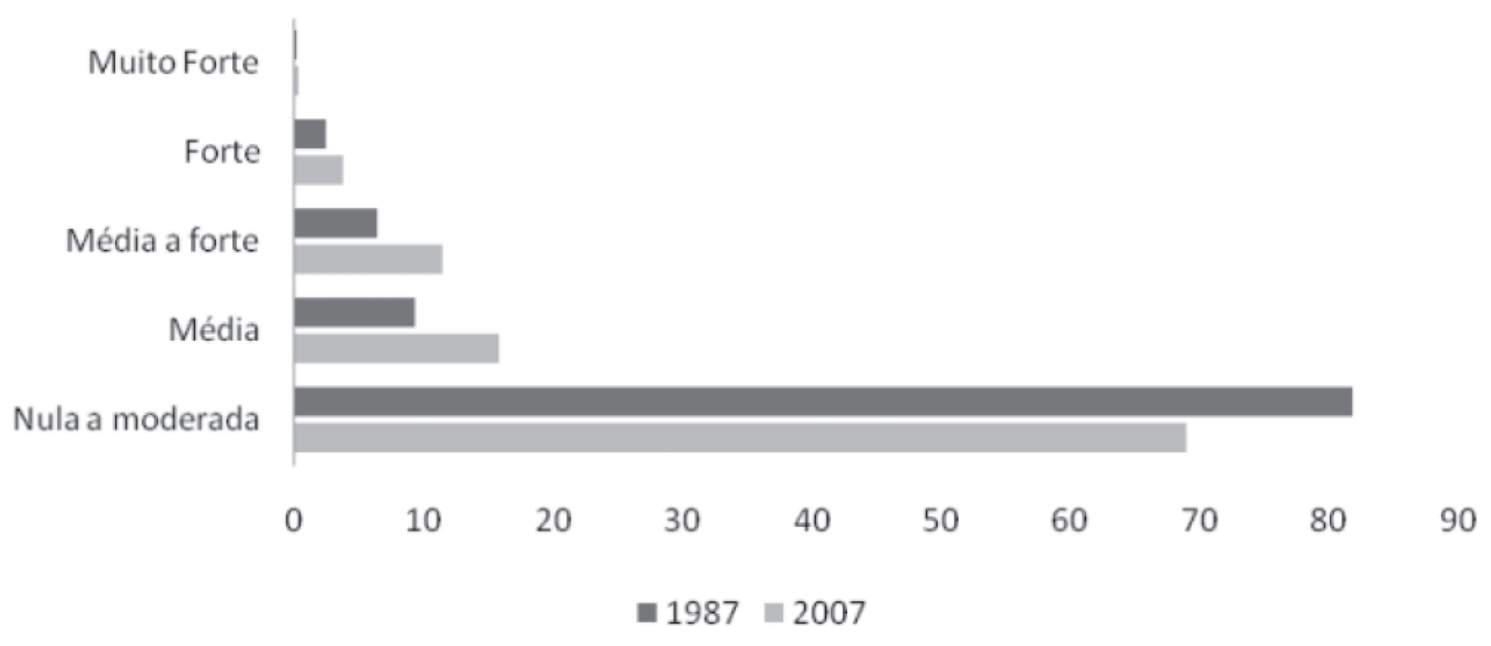

Figura 10. Análise Multitemporal da Erosão Atual em porcentagem (1987 - 2007).

média) e outros locais nem tão propícios como as áreas de moderada a forte perda de solo. A susceptibilidade erosiva tende a aumentar em iguais proporções que o avanço da agricultura. O novo cenário da expansão agrícola terá que ocupar áreas de menor potencial agrícola, com solos sazonalmente inundáveis ou em locais de média a alta declividade. Tais locais demandam maior investimento em tecnologias de correção das propriedades do solo, práticas mecânicas, vegetativas e de manejo . Não obstante, nota-se nas imagens de 2007 que alguns locais com declividade média já apresentam práticas conservacionistas que mitigam riscos de erosão favorecidos pelo relevo, a exemplo das plantações em curvas de nível. Tais medidas são fundamentais para compatibilizar o desenvolvimento agrícola à conservação ambiental e se utilizadas em larga escala podem dar novas perspectivas a área.

Por fim, por meio das análises dos mapas de Erosão Atual pôde-se perceber notável evolução de 1987 a 2007, o que ratifica a relevância e a modificação que o elemento antrópico traz para as análises acerca dos processos erosivos que alteram fortemente as propriedades do solo.

A susceptibilidade erosiva é bem representada pelos mapeamentos de erosão atual, que podem dar subsídios ao planejamento conservacionista com vistas ao desenvolvimento sustentável na área pesquisada.

Esta pesquisa pode embasar estudos de susceptibilidade e instalação de processos erosivos e dar base a demais estudos na Bacia do Rio Urucuia, como: (a) estudos de compartimentação do relevo; e (b) estudos de análise para subsidiar políticas publicas estratégicas para a efetiva aplicabilidade da legislação ambiental pertinente, serviços ambientais, entre outros.

\section{Agradecimentos}

Os autores agradecem o apoio recebido durante a realização deste trabalho do Conselho Nacional de Desenvolvimento Científico e Tecnológico ( $\mathrm{CNPq}$ ) pelas bolsas de pesquisa dos professores Osmar Abílio de Carvalho Júnior e Renato Fontes Guimarães, como também, pelo financiamento do Projeto "Modelo Integrado para o monitoramento e desenvolvimento sustentável da bacia do São Francisco" referente ao edital MCT/CNPq/MMA/MI/CTHIDRO - n ${ }^{\circ}$ 035/2006. Em especial os autores agradecem aos membros do Laboratório de Sistemas de Informações Espaciais (LSIE) da UnB pelas críticas e sugestões realizadas durante a elaboração do artigo.

\section{Referências Bibliográficas}

Ball, G \& Hall, D. (1967) A clustering technique for summarizing multivariate data. Behavioral Science, 12: 153-155.

Bertoni, J. \& Lombardi Neto, F. (1990) Conservação do solo. $2^{\mathrm{a}}$. ed. São Paulo: Ícone Editora. 335 p.

Bloise, G.L.F.; Carvalho Júnior, O.A.; Reatto, A.; Gimarães, R.F.; Martins, E.S. \& Carvalho, A.P. (2001) Avaliação da suscetibilidade natural à erosão dos solos da Bacia do Olaria - DF. Boletim de Pesquisa e Desenvolvimento - Embrapa Cerrados, 14 p.

Brasil. Ministério das Minas e Energia. Projeto Radambrasil (1982) Folhas SE.20/21 - Corumbá. Geologia, geomorfologia, pedologia, vegetação e uso potencial da terra. Rio de Janeiro. $452 \mathrm{p}$. 
Browning, P.C.L. \& Class, J.A. (1947) A method for determining the use and limitation of rotation and conservation practices in control of soil erosion in lowa. Soil Science Societyof America Proceedings, 23: $246-$ 249.

Campos J.E. \& Dardenne, M.A. (1997) Estratigrafia e Sedimentação da Bacia Sanfranciscana: Uma Revisão. Revista Brasileira de Geociências, 27 (3): 269-282.

Carvalho, N.O. (1994). Hidrossedimentologia Prática. Rio de Janeiro: CPRM, 372 p.

Chaves, H.M.L. (1994) Estimativa da erosão atual e potencial no Vale do São Francisco. Relatório Final de Consultoria. Brasília: CODEVASF/FAO, 35 p.

CODEVASF - Companhia de Desenvolvimento dos Vales do São Francisco e do Parnaíba (2002) Análise Multitemporal da dinâmica de alteração da conformação do leito do Rio São Francisco Trecho Médio. Resumo Executivo do Relatório Final.

Cook, H.L. (1936) The nature and controlling variables of the water erosion process. Soil Science Society of America Proceedings. 1: 487 - 494.

Curi, N.; Larach, J.O.I.; Kämpf, N.; Moniz, A.C. \& Fontes, L.E.F. (1993) Vocabulário de ciência do solo. Campinas: Sociedade Brasileira de Ciência do Solo, 89 p.

Denardin, J.E. (1990) Erodibilidade de solo estimada por meio de parâmetros físicos e químicos. $81 \mathrm{f}$. Tese (Doutorado) - Escola Superior de Agricultura Luiz de Queiroz, Piracicaba.

Desmet, P.J.J. \& Govers, G. (1996) A GIS procedure for automatically calculating the USLE LS factor on topographically complex landscape units. Journal of Soil and Water Conservation, 51 (5): 427-433.

EMBRAPA (1999) Sistema Brasileiro de Classificação de Solos. Brasília: Serviço de Produção de Informação EMBRAPA-EPI. 412 p.

Farinasso, M.; Carvalho Júnior, O.A.; Guimarães R.F.; Gomes R.A.T. \& Ramos V.M. (2006) Avaliação qualitativa do potencial de erosão laminar em grandes áreas por meio da eups - equação universal de perdas de solos utilizando novas metodologias em sig para os cálculos dos seus fatores na região do Alto Parnaíba - PI-MA. Revista Brasileira de Geomorfologia, 7 (2): 73-85.

Fernandes, M. do C. \& Menezes, P.M.L de (2005) Comparação entre métodos para geração de MDE para a obtenção de observações em superfície real no maciço da Tijuca-RJ. RBC - Revista Brasileira de Cartografia 57 (2): $154-161$.

Foster, G.R. \& Wischmeier, W.H. (1974) Evaluating irregular slopes for soils loss prediction. Transactions of the ASAE, 17: 305-309.

Guimarães, R. F. (2000) Utilização de um modelo de previsão de áreas susceptíveis à escorregamentos rasos com controle topográfico: Adequação $e$ calibração em duas bacias de drenagem. $156 \mathrm{f}$. Tese (Doutorado em Geografia) Universidade Federal do Rio de Janeiro (UFRJ), Rio de Janeiro.

Haggett, P. \& Chorley, R.J. (1967) Models, paradigms and the new geography. In: Chorley, R. J. \& Haggett, P. (Eds) Models in Geography. London: Methuen, p. $19-41$.

Harvey, D.W. (1969) Explanation in geography. London: Edward Arnold, 521p.

Hoyos, N. (2005) Spatial modeling of soil erosion potential in a tropical watershed of the Colombian Andes. Catena, 63 (1): 85 - 108.

Hutchinson, M.F. (1989) A new procedure for gridding elevation and stream line data with automatic removal of spurious pits. Journal of Hydrology, 106: 211-232.

IBGE - Instituto Brasileiro de Geografia e Estatística e IBDF Instituto Brasileiro do Desenvolvimento Florestal. (1988) Mapa de Vegetação do Brasil.1:5.000.000, Rio de Janeiro: IBGE.

Lombardi Neto, F. \& Bertoni, J. (1975) Erodibilidade de solos paulistas. Boletim Técnico do Instituto Agronômico de Campinas, n. 27, 12 p.

Lombardi Neto, F. \& Moldenhauer, W.C. (1980) Erosividade da chuva: sua distribuição e relação com perdas de solo em Campinas, SP. Bragantia, 51 (2): 189196.

Martins-Neto, M.A.; Pedrosa-Soares, A.C. \& Lima, S.A.A. (2001) Tectono sedimentary evolution of sedimentary basins from Paleoproterozoic to Late Neoproterozoic in the São Francisco craton and Araçuaí fold belt, eastern Brazil. Sedimentary Geology, 141-142: 343-370;

Merten, G.H.; Caviglione, J.H.; Ciaomini, D.C.; Rufino, R.L.; Medeiros, G.; Saintraint, D.; Ribas, G.C.; Dedecek, R. \& Kessler, C.A. (1995) El uso del SIG del modelo USLE para determinar mapas de erosion potencial y actual em lãs microcuencas pilotos 
Avaliação multitemporal da susceptibilidade erosiva na bacia do rio Urucuia (MG) por meio da EUPS

de Água Grande y Córrego do Pensamento, Mamborê, Paraná, Brasil. Santiago, Chile: Proyeto Regional GCP/RLA/107/JPN (FAO - Documento de Campo, 6) 43p.

Moore, I.D. \& Burch, G.J. (1986) Modeling erosion and deposition. Topographic effects. Transactions of the ASAE, 29 (6): 1624-1630.

O'Calaghan, J.F. \& Mark, D.M. (1984) The extraction of drainage network from digital elevation data. Computer Vision, Graphics, and Image Processing, 28: 328- 344.

Panachuki, E., Sobrinho, T.A., Vitorino, A.C.T., Carvalho, D.F de \& Urchei, M.A. (2006) Parâmetros físicos do solo e erosão hídrica sob chuva simulada, em área de integração agricultura-pecuária. Revista Brasileira de Engenharia Agrícola e Ambiental, $10(2): 261-268$.

Primavesi, A. (1987) Manejo ecológico do solo. 9a . Edição, São Paulo, Nobel, 549p.

Resende, M. (1985) Aplicações de conhecimentos pedológicos à conservação de solos. Informativo Agropecuário, 11 (128): 3 - 18.

Sampaio, C.E.M (1990) Análise de grupo via programação matemática. 95 f. Dissertação (Mestrado em Estatística) - Instituto de Ciências Exatas, Universidade de Brasília, Brasília.

Sgarbi, G.N.C. 1989. Geologia da Formação Areado. Cretáceo Inferior a Médio da Bacia Sanfranciscana, Oeste do Estado de Minas Gerais. 324 f. Dissertação (Mestrado em Geologia) - Universidade Federal do Rio de Janeiro, Rio de Janeiro.

Smith, D.D (1941) Interpretation of soil conservation data for field use. Journal of Agricultural Engineering, $22(5): 173-175$.

Spigolon, A.L.D. \& Alvarenga, C.J.S. (2002) Fácies e elementos arquiteturais resultantes de mudanças Climáticas em um ambiente desértico: Grupo Urucuia (neocretáceo), bacia sanfranciscana. Revista Braileira. de Geociências, 32 (4): 579 586.
Stein, D.P., Donzelli, P.L., Gimenez, A.F., Ponçano, W.L. \& Lombardi Neto, F. (1987) Potencial de erosão laminar, natural e antrópica, na Bacia do Peixe Paranapanema. In: Simpósio Nacional de Controle de Erosão, 4., Marília (SP). Anais. Marília: ABGE, p. $105-135$.

Tarboton, D. G. (1997) A new method for the determination of flow directions and upslope areas in grid digital elevation models. Water Resources Research, 33 (2): $309-319$.

Thornthwaite, C.W. (1948) An approach towards a rational classification of climate. Geographic Review, 38: 55-94.

Vilar, O.M. \& Prandi, E.C. (1993) Erosão dos solos. In: Cintra, J.C.A. \& Albiero, J.H. (Eds.). Solos do interior de São Paulo. São Carlos (SP): ABMS/USP. Cap. 7, p. 177-206.

Wischmeier, W.H. \& Smith, D.D. (1958) Rainfall energy and its relationship to soil loss. Transaction American Geophisical Union. Washington, 39: 285 - 291.

Wischmeier, W.H. \& Smith, D.D. (1965) Predicting rainfallerosion losses from cropland east of the Rocky Mountains-guide for selection of practices for soil and water conservation. Washington: United States - Department of Agriculture, 47 p. (USDA Agric. Handbook, n. 282).

Wischmeier, W.H.; Johnson, C. \& Cross, B. (1971) A soil erodibility nomograph for farmland and construction sites. Journal of Soil Water Conservation, 26 (2): 189-193.

Wischmeier, W.H. \& Smith, D.D. (1978) Predicting rainfall erosion losses; a guide to consevation planning. Washington: United States - Department of Agriculture, 58 p. (USDAAgric. Handbook, n. 537).

Zingg, R.W. (1940) Degree and length of land slope as it affects soil loss runoff. Journal of Agricultural Engineering, 21: 59-64. 
